\title{
The effect of watershed scale on HEC-HMS calibrated parameters: a case study in the Clear Creek watershed in Iowa, US
}

\author{
H. L. Zhang ${ }^{1,2}$, Y. J. Wang ${ }^{1}$, Y. Q. Wang ${ }^{1}$, D. X. Li $^{2}$, and X. K. Wang ${ }^{2}$ \\ ${ }^{1}$ Key Laboratory of Soil and Water Conservation and Desertification Combating, Ministry of Education, \\ School of Soil and Water Conservation at Beijing Forestry University, Beijing, 100083, China \\ ${ }^{2}$ State Key Laboratory of Hydroscience and Engineering, Tsinghua University, Beijing 100084, China
}

Correspondence to: Y. J. Wang (wyujie@bjfu.edu.cn) and H. L. Zhang (zhanghl@bjfu.edu.cn)

Received: 25 October 2012 - Published in Hydrol. Earth Syst. Sci. Discuss.: 22 January 2013

Revised: 15 May 2013 - Accepted: 8 June 2013 - Published: 15 July 2013

\begin{abstract}
In this paper, we use the Hydrologic Modeling System (HEC-HMS) to simulate two flood events to investigate the effect of watershed subdivision in terms of performance, the calibrated parameter values, the description of hydrologic processes, and the subsequent interpretation of water balance components. We use Stage IV hourly NEXRAD precipitation as the meteorological input for ten model configurations with variable sub-basin sizes. Model parameters are automatically optimized to fit the observed data. The strategy is implemented in Clear Creek Watershed (CCW), which is located in the upper Mississippi River basin. Results show that most of the calibrated parameter values are sensitive to the basin partition scheme and that the relative relevance of physical processes, described by the model, change depending on watershed subdivision. In particular, our results show that parameters derived from different model implementations attribute losses in the system to completely different physical phenomena without a notable effect on the model's performance. Our work adds to the body of evidence demonstrating that automatically calibrated parameters in hydrological models can lead to an incorrect prescription of the internal dynamics of runoff production and transport. Furthermore, it demonstrates that model implementation adds a new dimension to the problem of non-uniqueness in hydrological models.
\end{abstract}

\section{Introduction}

Watershed subdivision is frequently used in semi-distributed hydrologic models to capture spatial heterogeneities of distributed land cover and soil datasets and to characterize distributed inputs in different areas within the watershed. Watershed partitioning affects the setup of hydrologic models in several ways: (1) the watershed boundary delineation predetermines aggregation patterns of spatial information; (2) subbasin topographic parameter values (slope, aspect, etc.) are controlled by sub-basin size and extent; and (3) different delineations of river network connectivity and hillslope size can lead to the misrepresentation of rainfall-runoff production on hillslopes and flow transport in channels. Consequently, delineation of sub-watersheds has the potential to affect model outputs. The emphasis on the effect of watershed size has contributed to a more complete understanding of the hydrological cycle and is crucial to the investigation of how well model input parameters will describe the watershed system and how land cover and soil texture alter water cycle components.

Several studies have used a variety of well-established hydrologic models to investigate the effect of sub-watershed size on hydrologic model outputs. These studies include the Soil and Water Assessment Tool (SWAT) model (Tripathi et al., 2006; Muleta et al., 2007; Kumar and Merwade, 2009), MUSIC (Elliott et al., 2009), BTOPMC (Ao et al., 2003), the Storm Water Management Model (SWMM) (Ghosh and Hellweger, 2011), and the Hydrologic Modeling System (HEC-HMS) (Chen et al., 2011; Cleveland et al., 2009). These studies have investigated how watershed aggregation 
affects peak discharge and flow volume. In spite of the consensus on the importance of selecting the correct watershed partitioning size, conclusive guidelines for the most appropriate partitioning scheme for semi-distributed hydrological models have not yet been established because of the diversity of model structures used, the large number of calibrated parameters, and the different topographic and geospatial features of study sites. For example, it has been shown that subwatershed size affects the determination of peak flow magnitude and that the effect changes for different storm types (Ghosh and Hellweger, 2011). Some researchers claim contradictory results regarding the effect of sub-watershed size on determining peak flow magnitudes (Ao et al., 2003; Kumar and Merwade, 2009; Ghosh and Hellweger, 2011). Some have reported that larger sub-watersheds decrease flood peak (Muleta et al., 2007), while others have concluded that the effect can be neglected (Cleveland et al., 2009; Chen et al., 2011). On the other hand, most of the previous studies found that flood volume is largely insensitive to watershed partitioning. All of these studies have focused on the effects of watershed partitioning on peak flow and water volume; however, these investigations have not fully addressed the effect of watershed portioning on the model's representation/accuracy of the internal dynamics of the hydrologic process that can be interpreted from model parameters.

This study investigates the effect of watershed partitioning on model parameter values that are estimated via an automatic calibration procedure. Model parameters describe different hydrological processes and lead to a unique interpretation of the water balance components. We analyze differences in such interpretations while simultaneously evaluating model performance with respect to peak flow magnitude and runoff volumes. We use the Hydrologic Modeling System model developed by the Hydrologic Engineering Center (HEC-HMS), which has a large number of parameters that can be calibrated. Because, in the HEC-HMS, the total runoff at the outlet of a watershed is a combination of the hillslope and channel runoff values, parameters can be classified as either hillslope related or river channel related.

Watershed subdivisions can be altered to enhance the utility of distributed input information in both basin and river levels at the expense of increasing the model's complexity (i.e. number of parameters). As a result, high-resolution subbasins can either increase or decrease model performance, which makes it difficult to determine an optimal sub-basin size. Furthermore, the difficulty in finding unique parameter sets in complex models has been reported in the literature (Gan and Bitfu, 1996; Vrugt et al., 2003) and has been attributed to the various uncertainties inherent in both the model and real systems (Moradkhani et al., 2005). Consequently, the calibration procedures involving "manual" or "automatic" adjustments to parameter values in order to closely match the output model behavior to observations complicate this problem.
In this study, we focus on the effect the sub-watershed scale has on the relevance of different hydrologic processes, and we are also concerned with the physical interpretations of internal dynamics, which are reflected in changing parameter values. Very limited studies have been conducted to evaluate water balance components. Tripathi et al. (2006) used SWAT to investigate the effect of watershed subdivision upon various components of water balance on a distributed scale and found obvious variations of evapotranspiration, percolation, and soil water content with change in subdivision pattern, even though there was little influence on annual runoff values. Their research has substantially increased our understanding of water balance distribution on a spatial scale. However, reasons for variations of water balance components have not been fully investigated. In this study, we investigate fraction variations of water balance components in HECHMS (i.e. surface flow, baseflow, water abstraction in hillslope and channel loss) due to watershed size changes and particularly stress the interpretation of parameter values with regard to water balance components.

This paper is organized as follows: we begin by introducing the study site and data, followed by a description of the HEC-HMS model and key parameters. Then, we discuss our methodology for watershed subdivision, the HEC-HMS model's calibration and validation, and the separation of water balance components. The subsequent sections explain the hydrologic simulations using ten model configurations that we conducted in Clear Creek Watershed (CCW) for two flood events, the results of scale effects of sub-watershed on watershed attributes and model performance, and the calculated calibrated parameter values. We then discuss the interpretation of the model parameters to the physical water balance and end with a discussion of results and conclusions.

\section{Study site and data}

The Clear Creek Watershed (HUC-10: 0708020904), shown in Fig. 1, is located at the intersection of Iowa County and Johnson County, in east central Iowa, USA. The watershed's $260 \mathrm{~km}^{2}$ area is predominantly covered by agricultural land, but it also includes wetlands and urbanized catchments with elevations ranging from $189 \mathrm{~m}$ to $278 \mathrm{~m}$. A $10 \mathrm{~m}$ resolution DEM and the stream network provided by the Natural Resources Geographic Information Systems Library (NRGISL) are used to delineate sub-basin models.

This watershed is the current site for multiple studies on soil erosion due to the heavy row cropping and loose soil (e.g. Papanicolaou et al., 2008). Land use data for CCW obtained from the National Land Cover Dataset (NLCD) indicate that the watershed contains agricultural (57.1\%), herbaceous $(22.8 \%)$, urban (13.3\%), forest (5.8\%), and water body $(1.0 \%)$ land uses. Soil data was obtained from the Soil Survey Geographic (SSURGO) database form the US Department of National Resource Conservation Service 


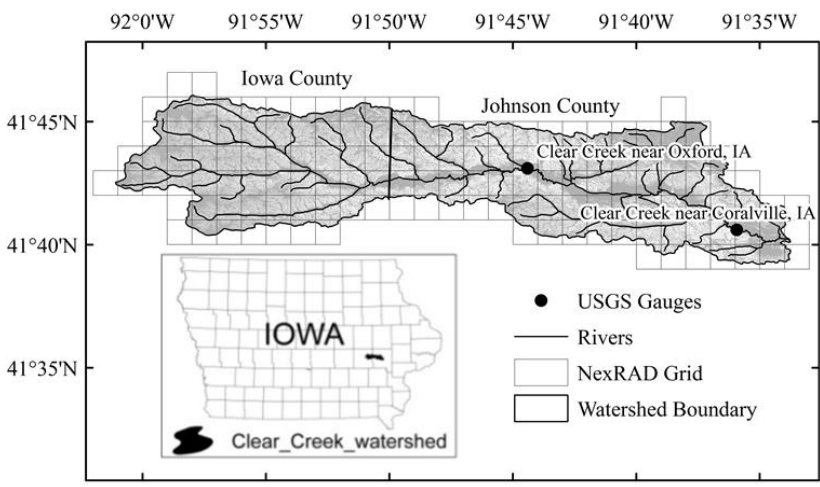

Fig. 1. Location map of Clear Creek Watershed.

(NRCS) and is classified as four hydrologic soil groups: A (sands and gravel, 10.0\%), B (loam, 68.4\%), C (silty-loam, $16.9 \%$ ), and D (clay, $4.7 \%$ ) (for details see Hydrology National Engineering Handbook, 2007). Sandy loam soils with moderate infiltration rates are the most prevalent in the watershed.

CCW receives an average annual precipitation of $889 \mathrm{~mm}$, and the average annual runoff is $68 \times 10^{6} \mathrm{~m}^{3}$ (USGS annual statistics from 1953 to 2011). Hourly precipitation Stage IV products for this region, which are a mosaic of regional, multi-sensor analyses produced by the National Weather Service (NWS) River Forecast Centers (RFCs), are provided by the National Centers for Environmental Prediction (NCEP) (Lin and Mitchell, 2005). The NEXRAD grid $\left(1^{\prime} \times 1^{\prime}\right)$ is shown in Fig. 1. The watershed is gauged near the outlet of the basin (Clear Creek near Coralville) as well as at an interior location (Clear Creek near Oxford) (see Fig. 1). Hourly discharge time series at these two locations are provided by the US Geological Survey (USGS).

We consider two different flood events in this study. The first is the June 2008 extreme flood in eastern Iowa. Total precipitation in the year 2008 is about $1210 \mathrm{~mm}$, exceeding $36 \%$ of the annual rainfall, mainly due to the known June 2008 extreme flood. In June, the total rain amount is $226 \mathrm{~mm}$, and the overall time duration is $66 \mathrm{~h}$ with hourly rainfall intensity values above $15 \mathrm{~mm} \mathrm{~h}^{-1}$. Meanwhile, the antecedent conditions to this period are dominated by high initial soil moisture in the basin. Therefore, the period of June was characterized by short and intense precipitation events, which are usually associated with flash flooding conditions (NESDIS, 2008). The catastrophic flooding in June 2008 occurred throughout most of the Upper Mississippi River basin (Mutel, 2010). The second period covers April 2008. This is a smaller event in magnitude, with total rainfall amount of $168 \mathrm{~mm}$, duration of $106 \mathrm{~h}$, and general rainfall intensity of $5-10 \mathrm{~mm} \mathrm{~h}^{-1}$. The antecedent conditions are different from those of June.

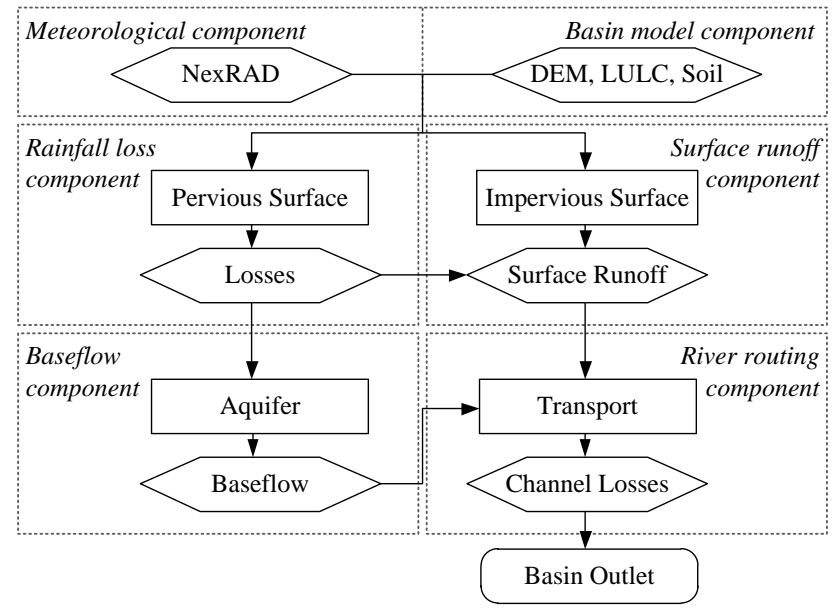

Fig. 2. Schematic of rainfall-runoff processes in HEC-HMS.

\section{Description of the hydrologic model}

\subsection{The HEC-HMS model}

HEC-HMS is a physically based, semi-distributed hydrologic model developed by the US Army Corps of Engineers to simulate the hydrologic response of a watershed subject to a given hydrometeorological input (Scharffenber et al., 2010). The model uses underlying DEM information to partition the basin into sub-watersheds. The size of the subwatershed is determined a priori by the modeler, and few or no guidelines are available for sub-watershed selection. In most cases, the balance between the resolution of the distributed information and the computation time required for simulation is the main factor considered for this selection. The model can simulate individual storm events as well as continuous precipitation input at minute, hourly, or daily time steps. Figure 2 depicts a schematic of the river basin rainfallrunoff process structure.

\subsection{Parameters in HEC-HMS}

The HEC-HMS offers a variety of model options to simulate runoff production, at the hillslope scale and flow channels (see Fig. 2). These include SCS curve number, SCS unit hydrograph, and baseflow estimation methods which are necessary to calculate water losses, runoff transformation, and baseflow rates. In our study, the Muskingum and constant loss method are used to calculate flood routing and water losses along the channel. The values of the model parameters have the potential to change along with changing sub-basin sizes. We provide a description of the governing equations and the physical meaning of model parameters for hillslope and channel processes here and will subsequently use them to analyze their behavior as the size of the sub-watersheds changes. 
Hydrologic mechanisms on hillslope include losses due to ponding, infiltration, and baseflow production. The SCS loss model for basin loss is given by

$P_{\mathrm{e}}=\left(P-I_{\mathrm{a}}\right)^{2} /\left(P-I_{\mathrm{a}}+S\right)$,

where $P_{\mathrm{e}}$ is excess precipitation, $P$ is accumulated precipitation, $I_{\mathrm{a}}$ is initial abstraction and can be initialized as $0.2 \mathrm{~S}$, and $S$ is the potential maximum retention and is a function of curve number $(\mathrm{CN}): S=(25400-254 \mathrm{CN}) / \mathrm{CN}$ (SI system) (USACE, 2000). The initial abstraction and $\mathrm{CN}$ are required parameters.

The SCS unit hydrograph (UH) rainfall-runoff transformation model is a dimensionless unit hydrograph $U_{t}$ expressed as a ratio to peak (RP) discharge $U_{\mathrm{p}}$ for any fraction of time $t / T_{\mathrm{P}}$, where $T_{\mathrm{P}}$ is the time to peak. The peak discharge is given by $U_{\mathrm{P}}=\mathrm{CA} / T_{\mathrm{P}}$, where $C$ is the conversion constant (2.08 in SI) and $A$ is the sub-watershed area. The time of peak $T_{\mathrm{P}}$ is calculated as $T_{\mathrm{P}}=\Delta t / 2+t_{P}$, where $\Delta t$ is the time step in HEC-HMS and $t_{\mathrm{p}}$ is the time lag defined as the time difference between the center of excess precipitation and the center of UH (USACE 2000). $t_{\mathrm{P}}$ is a required input parameter.

The exponential recession model for baseflow is given by

$Q_{t}=Q_{0} k^{t}$

where $Q_{0}$ is initial baseflow and $k$ is an exponential decay constant. During the recession period of a flood event, a RP is specified to derive the threshold flow at which the baseflow is calculated as a fraction of peak flow. $Q_{0}, k$ and the RP are required parameters.

Hydrologic mechanisms in the transport in the channel contain Muskingum parameters and constant channel loss. The Muskingum model is frequently used for flood routing in natural channels (Chu and Chang, 2009). The continuity and storage equation in mathematical terms is expressed as

$\frac{\mathrm{d} W}{\mathrm{~d} t}=I-Q ; W=K[x I+(1-x) Q]$,

where $W$ is channel storage; $I$ and $Q$ are inflow and outflow rates, respectively; $K$ is storage time for a channel and is estimated as $K=L / V_{\mathrm{m}}$, where $L$ is channel length and $V_{\mathrm{m}}$ is flow wave velocity; and $x$ is a weighting factor varying from 1 to 0.5 that can be estimated as $\frac{1}{2}\left(1-\frac{Q_{0}}{\mathrm{BS}_{0} V_{\mathrm{m}} L}\right)$. $Q_{0}$ is the reference flow, $B$ is the top width of flow area, and $S_{0}$ is the friction slope (Cunge, 1969). $K$ and $x$ are required parameters. Water loss through channels is approximated by a constant channel loss method. The two critical parameters in this model are the constant flow rate subtracted and the ratio that is remaining.

HEC-HMS has eight parameters associated with stream flow calibration, some of which are defined at hillslope level while others are defined at the river channel level. Parameter variability (PV) is used to describe parameter variation regarding the selection of sub-watershed sizes (see Eq. 4). In

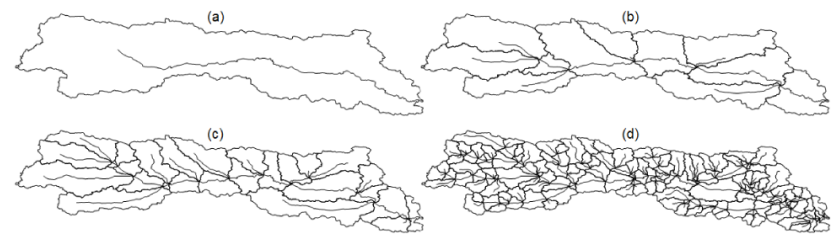

Fig. 3. Configurations of CCW discretization with numbers of subbasins: (a) $N=1, \bar{A}=265 \mathrm{~km}^{2}, L=38 \mathrm{~km}$; (b) $N=11, \bar{A}=24 \mathrm{~km}^{2}$, $L=64 \mathrm{~km}$; (c) $N=27, \bar{A}=9.8 \mathrm{~km}^{2}, L=106 \mathrm{~km}$; and (d) $N=157$, $\bar{A}=1.7 \mathrm{~km}^{2}, L=197 \mathrm{~km}$.

addition, we consider parameter values for different floods, so PVf in Eq. (5) is used to describe differences of parameter values during different flood events.

$\mathrm{PV}=\frac{S_{\max }-S_{\min }}{\bar{S}} \times 100 \%$

$\mathrm{PVf}=\frac{\overline{\left(S_{i}-S_{j}\right)}}{S_{j}} \times 100 \%$

where $S_{\max }, S_{\min }$ and $\bar{S}$ are the maximum, the minimum, and the mean values of the calibrated parameter for all configurations, respectively; $i$ and $j$ stand for the $i$ th or $j$ th flood event.

\section{Methodology}

The methodological approach can be divided into four major tasks: (1) creating ten configurations with different numbers of sub-watersheds; (2) simulating and calibrating the rainfall-runoff process; (3) analyzing parameters and the relationship between parameter values and the corresponding sub-basin areas; and (4) determining the role of model selection (watershed size) in the interpretation of water balance.

\subsection{Watershed subdivisions}

In HEC-HMS, a river basin is divided into a number of subwatersheds based on a critical area threshold for the stream generation. The threshold is the minimum upstream drainage area for a channel to originate and can be specified by a percentage of total watershed area (Kumar and Merwade, 2009). In this study, threshold area is specified for river generation, and the values are listed in Table 1 .

The realization of the discretization over the basin area is then conducted based on pre-processing software GeoHMS, an add-on of ArcGIS. Configurations with 1, 11, 27, and 157 are shown in Fig. 3.

\subsection{Model calibration and assessment}

The initial step in model calibration is a manual adjustment of model parameters using the trial-and-error method, which 
Table 1. Area threshold for watershed division.

\begin{tabular}{lrrrrrrrrrr}
\hline Number of sub-basins & 1 & 7 & 9 & 11 & 17 & 23 & 27 & 45 & 81 & 157 \\
Threshold $\left(\mathrm{km}^{2}\right)$ & 30 & 25 & 16 & 13 & 10 & 5 & 3.9 & 2.8 & 1.45 & 0.84 \\
\hline
\end{tabular}

enables the modeler to make a subjective adjustment of parameters that gives an appropriate fit between observed and simulated hydrographs (Oleyible and $\mathrm{Li}, 2010$ ). An automatic optimization algorithm built into the HEC-HMS 3.4 implementation follows this step. HEC-HMS 3.4 provides seven objective functions for automated parameter estimation. These include the sum squared residuals (SSR), which emphasize water balance; peak error (PE); mass balance error (MBE); the Nash-Sutcliffe efficiency coefficient $\left(E_{\mathrm{NS}}\right)$, and the relation coefficient $\left(R^{2}\right)$ (Kalin and Hantush, 2006). The SSR measurement is chosen for CCW modeling calibration. The SSR measurement is the sum of the squared differences between observed and simulated flow and gives greater weight to large errors and lesser weight to small errors (USACE, 2000). Thus, the objective function is defined as

$\mathrm{RRS}=\sum_{t=1}^{n}\left(Q_{\mathrm{o}}-Q_{\mathrm{S}}\right)^{2}$,

where $Q_{\mathrm{o}}$ and $Q_{\mathrm{s}}$ are observed and simulated flow, respectively, while the other measures of $\mathrm{PE}, \mathrm{MBE}, E_{\mathrm{NS}}$, and $R^{2}$ (Kalin and Hantush, 2006) are used to assess the hydrological modeling performance. The performance measures are defined as

$\mathrm{PE}=\frac{Q_{\mathrm{s}, \mathrm{m}}-Q_{\mathrm{o}, \mathrm{m}}}{Q_{\mathrm{o}, \mathrm{m}}}$

$\mathrm{MBE}=\frac{\sum i=1^{n} Q_{\mathrm{s}}-\sum_{i=1}^{n} Q_{\mathrm{o}}}{\sum_{i=1}^{n} Q_{\mathrm{o}}}=\frac{\overline{Q_{\mathrm{s}}}-\overline{Q_{\mathrm{o}}}}{\overline{Q_{\mathrm{o}}}}$

$E_{\mathrm{NS}}=1.0-\frac{\sum i=1^{n}\left(Q_{\mathrm{s}}-\overline{Q_{\mathrm{o}}}\right)^{2}}{\sum_{i=1}^{n}\left(Q_{\mathrm{o}}-\overline{Q_{\mathrm{o}}}\right)^{2}}$

$R^{2}=\frac{\left[\sum_{i=1}^{n}\left(Q_{\mathrm{s}}-\overline{Q_{\mathrm{s}}}\right)\left(Q_{\mathrm{o}}-\overline{Q_{\mathrm{o}}}\right)\right]^{2}}{\left[\sum_{i=1}^{n}\left(Q_{\mathrm{s}}-\overline{Q_{\mathrm{s}}}\right)^{2}\right]\left[\sum_{i=1}^{n}\left(Q_{\mathrm{o}}-\overline{Q_{\mathrm{o}}}\right)^{2}\right]}$,

where $Q_{\mathrm{o}, \mathrm{m}}, \overline{Q_{\mathrm{o}}}$, and $Q_{\mathrm{o}}$, are observed peak discharge, averaged discharge, and discharge at any time $t$, respectively, and $Q_{\mathrm{s}, \mathrm{m}}, \overline{Q_{\mathrm{s}}}$, and $Q_{\mathrm{s}}$ are corresponding calculated discharge values.

\subsection{Water balance components}

Major model components include basin models, meteorological models, and control specifications; while hydrologic
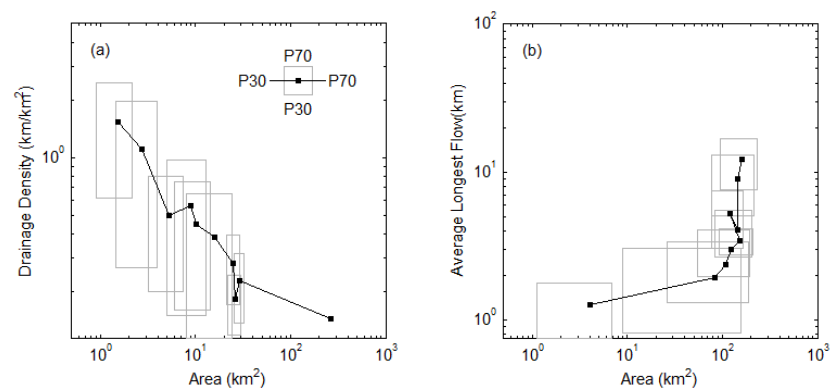

Fig. 4. Scaling property of watershed attributes associated with ranges of watershed areas.

cycle components contain precipitation, abstraction, surface runoff, baseflow, and open channel flow (Scharffenber et al., 2010), which were classified into two groups in this study: water amount flowing in (surface flow and base flow) and water amount flowing out (initial abstraction and channel loss) of the watershed. The former contributes to discharge while the latter reduces stream flow. The water balance over the whole watershed is given by components that increase and decrease water amount and can be formulated as:

$Q_{\mathrm{d}}+Q_{\mathrm{b}}-Q_{\mathrm{c}}=R$,

where $Q_{\mathrm{d}}, Q_{\mathrm{b}}$, and $Q_{\mathrm{c}}$ are the total volumes of direct flow, baseflow, and channel loss, respectively. $R$ is the discharge volume at the outlet. Here, $Q_{\mathrm{d}}$ is a function of precipitation and initial abstraction. Assuming the differences of total basin runoff for the ten configurations are negligible by model calibration with SSR as the objective function, it is possible to consider the effect of watershed sizes on water balance components.

\section{Results}

\subsection{Changes in watershed attributes}

We begin this section by showing how sub-watershed attributes change for different portioning schemes. Watershed attributes play an important role in determining hydrologic response for a given meteorological condition. Primary watershed attributes in HEC-HMS include drainage density and longest river length, which define water producing mechanisms and affect water transportation through a channel, respectively. Figure 4 depicts the ranges of those two dominant attributes associated with ranges of watershed areas. 

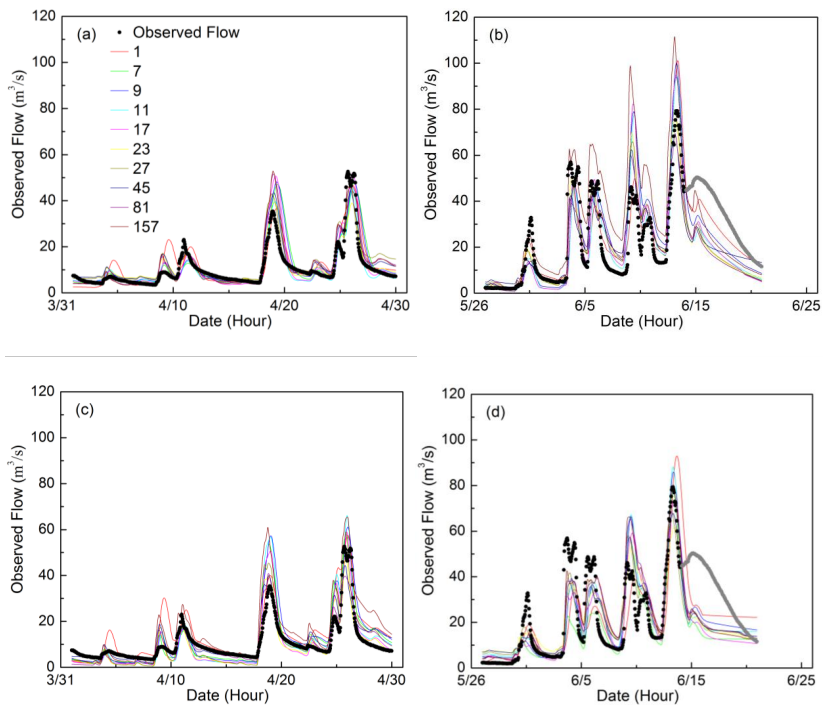

Fig. 5. Calculated hydrographs at Coralville with scenarios of (a) April, (b) June, (c) April flood with parameters of June (PJ), and (d) June flood with parameters of Aprill (PA).

Figure 4 illustrates that the mean of drainage density tends to decrease as the mean of sub-watershed area increases, while the average of longest flow length within each subwatershed increases. This result is similar to that found by Kumar and Merwade (2009). Further, we find that the function of averaged drainage density and averaged longest flow length versus averaged basin areas follows a power law. In Fig. 4, boxes have been drawn around the average values of watershed attributes as well as sub-basin areas that indicate the 30th and 70th percentiles of the distribution of values. In other words, variability of the drainage density and longest flow channel changes according to watershed areas. Note that the ranges of sub-basin areas in Fig. $4 \mathrm{a}$ and $\mathrm{b}$ are different. In the case of the drainage density plot, watershed area is defined as the unnested area of the watershed. However for the longest river flow it is defined as total irrigation area upstream from the upper node of the link.

The parameter that encapsulates the characteristics of land cover and soil type is the SCS curve number, which is calculated from the overlapping datasets of land use and hydrologic soil groups (Merwade, 2010). For CCW, we found that it varies between 74.9 and 76.1. Only small differences are detected between averaged $\mathrm{CN}$ values for the ten watershed configurations and, thus, are not presented here.

\subsection{Model performance under different watershed subdivisions}

The HEC-HMS model has been applied to the time periods of 1 April to 30 April 2008 and 27 May to 21 June 2008, considering the entire basin as a single lumped unit and as nine other configurations with various sub-watershed configurations. We designed four scenarios to better demonstrate
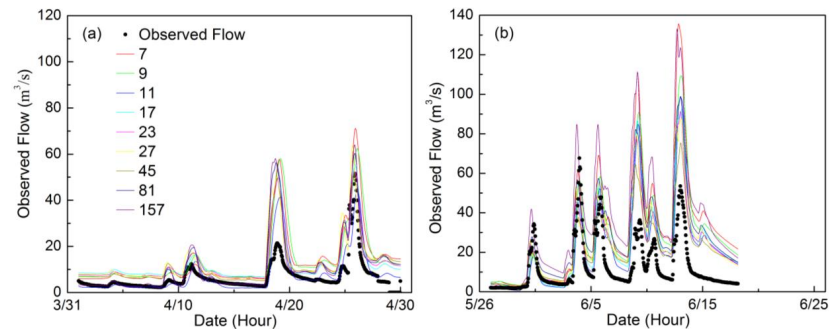

Fig. 6. Calculated hydrographs at Oxford with scenarios of (a) April and (b) June.

the behavior of parameters under different flood conditions. First, the April and June floods are simulated independently, and parameters are calibrated using an automatic calibration procedure. Second, for cross validation, the April flood is simulated using the calibrated parameters for June, and, similarly, the June flood is simulated using calibrated parameters for April. Outputs of hourly stream flows from the four scenarios are compared and depicted in Fig. 5a-d, respectively, with each containing ten configurations. Outflow at the interior point of CCW is also recorded to assess the model's ability to simulate internal dynamics. Hydrographs of April and June near Oxford are presented in Fig. 6a and b.

Most of the calibrated hydrographs for the April and June floods shown in Fig. 5a and b agree well with observations; however, we noticed a systematic bias in the estimation of peak flows. Note that the model failed to reproduce the big bump (grey dots in Fig. 5) following the largest peak for the June flood at Coralville (Fig. 5b). We found this anomaly in the data to be explained by backwater effects from the Iowa River downstream from the gauging station during the flood period. When the calibrated parameter set for the June flood data are used to simulate the April flood (Fig. 5c), we observed a similar performance. However, when we simulated the June flood using the April calibrated parameter set (Fig. 5d), we observed a systematic underestimation of peak discharges. Differences among these four scenarios reflect the mechanisms that are prioritized by the calibration process for these different types of floods.

In Fig. 6, simulated hydrographs at internal watersheds for our ten partition configurations are compared to streamflow data at the Oxford gauge (see Fig. 1 for gauge location). The comparison shows that all flow peaks are overestimated. This is an important indication that model performance at the outlet does not translate to the ability of the HEC-HMS to describe the interior dynamics of water in the basin.

Model performance is assessed using four performance indicators, namely the $E_{\mathrm{NS}}, R^{2}, \mathrm{MBE}$, and PE listed in Table 2 . The selected objective calibration function is given by RRS in Eq. (6), which ensures the accuracy of water mass conservation $(|\mathrm{MBE}| \leq 15 \%)$. Overall, peak values for April are mostly underestimated, while the first peak of April is overestimated. For the June flood, assessment indicators are 

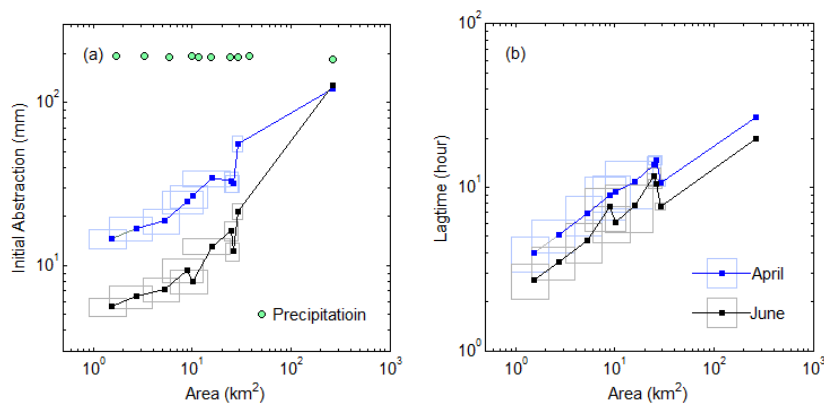

Fig. 7. Scaling property of HEC-HMS calibrated parameters on hillslope I (surface flow).

comparably low due to the observed backwater effect mentioned previously. Generally, $E_{\mathrm{NS}}$ and $R^{2}$ for configurations with a medium number of sub-basins (7-27) are higher than those with an extremely large (157) or small (1) number of sub-basins. Indicators for the last two scenarios are acceptable, showing that the hydrological modeling is stable.

\subsection{Analysis of calibrated parameter values}

In earlier sections, we showed that parameters corresponding to watershed attributes exhibit a systematically changing pattern when the number of sub-basins changes. Similarly, the values of calibrated parameters can change for different configurations. We investigated this phenomenon for the two flood events considered in this study. In order to understand variations of calibrated parameter values for the April and June floods in 2008, we group parameters into three sets depending on their physical meanings: parameters influencing surface flow on hillslope, baseflow from hillslopes, and flow in the channel.

First, the parameters contributing to hillslope surface processes include the initial abstraction (IA) and the lag time (LT). These two parameters determine how much direct surface runoff is produced and how it is delivered to channels. It can be seen in Fig. 7 that both IA and LT have a tendency to increase with increasing average sub-watershed areas, even though total precipitation volumes over the whole area for different configurations is kept constant. This tendency indicates that rainfall is more likely to be lost on hillslopes as watershed size increases. Boxes have been drawn around the mean values to indicate the spread of the parameter distributions. Lag times exhibit larger percentile ranges than those of IA for all configurations, but little difference is seen between percentile ranges for IA and LT during different floods. However, the absolute values of IA and LT are larger for the April flood (colored in grey in Fig. 7) than for the June flood (colored in black). The differences in parameter values in different floods indicate that hillslopes are more likely to produce surface flow instead of allowing infiltration that is later transformed into baseflow, demonstrating that the underestimation of June flood discharges by digesting April param-
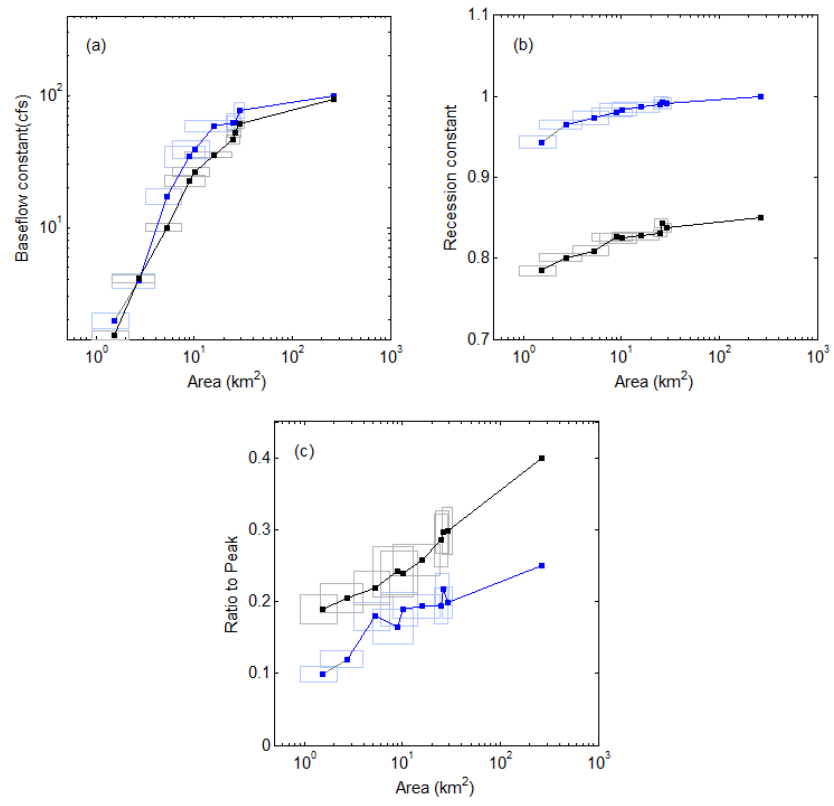

Fig. 8. Scaling property of HEC-HMS calibrated parameters on hillslope II (baseflow).

eters is partially caused by the larger amount of abstraction and the inertia tendency to transform rainfall to surface flow (depicted in Fig. 5d). This difference is also consist with the rainfall pattern that small but persistent rainfall in April results in larger abstraction and needs more time for surface flow to transform into baseflow, while flash precipitation in June tends to produce more surface flow in less time.

Second, parameters controlling baseflow production are the initial baseflow rate (IB), the recession constant (RC), and the RP. Estimated parameter values are shown in Fig. 8. In general, parameter variations associated with the baseflow component are confined to small ranges within different subbasin configurations. The variations among different configurations tend to increase as the average sub-basin size grows. For different floods, the RP and RC values show a different ratio in relation to the two floods analyzed. The value of $\mathrm{RC}$ for April is larger than that for June, while the RP is smaller. The value of IB remains approximately constant for the two events. In the exponential recession model, RP and RC values affect the flood recession process and are connected to the internal dynamic and interaction of surface and subsurface flow for different floods.

Finally, parameters related to flow transport in channels (shown in Fig. 9) are the Muskingum coefficient $(K)$, the channel loss rate (CLR), and the channel loss fraction (CLF). In contrast with calibrated parameters for baseflow processes, parameters in the river channel show large variations for almost all configurations and are much smaller between the different floods, but, in general, parameter values for the river channel increase as sub-basin size increases. 
Table 2. Calibration performance indicators for 10 configurations and 2 flood events (with 4 simulation scenarios).

\begin{tabular}{|c|c|c|c|c|c|c|c|c|c|c|c|c|c|c|c|c|}
\hline \multirow{2}{*}{$\begin{array}{l}\text { Configu- } \\
\text { rations }\end{array}$} & \multicolumn{4}{|c|}{2008.4} & \multicolumn{4}{|c|}{2008.6} & \multicolumn{4}{|c|}{2008.4 with PJ } & \multicolumn{4}{|c|}{2008.6 with PA } \\
\hline & MBE & $\mathrm{EP}$ & $E_{\mathrm{NS}}$ & $R^{2}$ & MBE & $\mathrm{EP}$ & $E_{\mathrm{NS}}$ & $R^{2}$ & MBE & $\mathrm{EP}$ & $E_{\mathrm{NS}}$ & $R^{2}$ & MBE & $\mathrm{EP}$ & $E_{\mathrm{NS}}$ & $R^{2}$ \\
\hline 1 & 12.6 & -11.1 & 0.53 & 0.70 & -4.2 & 27.7 & 0.77 & 0.78 & 35.9 & 9.7 & 0.50 & 0.80 & -11.2 & 17.3 & 0.48 & 0.54 \\
\hline 7 & 10.3 & -9.1 & 0.56 & 0.71 & -9.0 & 0.9 & 0.53 & 0.57 & 13.6 & 10.2 & 0.61 & 0.85 & -30.3 & -2.7 & 0.36 & 0.52 \\
\hline 9 & 14.1 & -7.5 & 0.69 & 0.76 & -1.4 & 20.3 & 0.54 & 0.64 & 19.1 & 16.1 & 0.46 & 0.84 & -11.1 & 8.5 & 0.55 & 0.60 \\
\hline 11 & -5.9 & -10.9 & 0.83 & 0.83 & -10.5 & 19.7 & 0.55 & 0.65 & 3.3 & 25.7 & 0.52 & 0.84 & -11.9 & 11.4 & 0.51 & 0.56 \\
\hline 17 & 6.1 & -0.9 & 0.69 & 0.80 & -9.3 & 18.6 & 0.55 & 0.65 & -6.8 & 12.0 & 0.67 & 0.84 & -18.5 & -8.0 & 0.43 & 0.51 \\
\hline 27 & 15.7 & -9.3 & 0.77 & 0.83 & -9.0 & 0.9 & 0.55 & 0.60 & -1.4 & 12.2 & 0.69 & 0.82 & -11.4 & -11.3 & 0.54 & 0.56 \\
\hline 45 & 13.7 & -15.9 & 0.80 & 0.84 & -10.2 & -10.1 & 0.56 & 0.58 & 10.1 & -15.8 & 0.76 & 0.78 & -12.5 & -14.3 & 0.54 & 0.57 \\
\hline 81 & 17.1 & -1.9 & 0.70 & 0.84 & -13.7 & -12.3 & 0.52 & 0.56 & -0.2 & -22.3 & 0.70 & 0.82 & -2.1 & 1.4 & 0.46 & 0.52 \\
\hline 157 & 13.5 & 0.5 & 0.53 & 0.84 & 35.2 & 40.9 & 0.13 & 0.47 & 45.1 & 24.4 & 0.15 & 0.82 & -2.8 & 0.0 & 0.42 & 0.49 \\
\hline
\end{tabular}
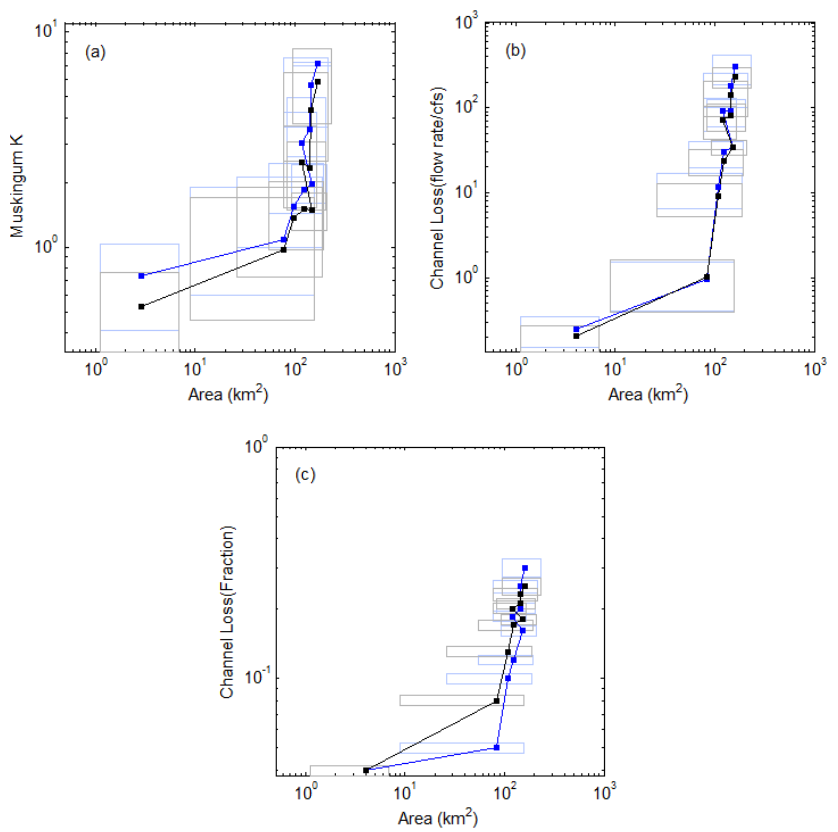

Fig. 9. Scaling property of HEC-HMS calibrated parameters in the channel.

PVs relative to watershed sizes and to floods are quantified by Eqs. (4) and (5). The results of the analysis for the April and June floods are listed in Table 3. A larger PV value suggests a greater difference of parameter values between different configurations or between different events.

Generally, parameters at hillslope vary more widely than parameters in the river channel for different floods, while variability of parameters in the channel is more sensitive to different configurations. This conclusion can also be observed from Figs. 7 to 9 .

\section{Discussion of results}

We have assessed the present effects of watershed subdivisions on the simulated water balance components of $\mathrm{CCW}$, considering ten configurations. As mentioned in the previous paragraph, water balance components in HEC-HMS simulations, including surface flow, baseflow, initial abstraction, and channel loss, are classified as flow contribution or flow deduction, respectively. As one of the primary principles for water balance analysis in the HEC-HMS model, the amount of water contributing to the discharge should be equal to that of the water amount deducing the discharge. In this study, water balance components consist of precipitation (contributing), abstraction (deducing), baseflow (contributing), and channel loss (deducing).

Specifically, we calculated the average values of components comprising the above two classifications for each configuration. Then, we quantified the proportions of surface flow to baseflow and the abstraction (loss in hillslopes) to the loss in channel to investigate the watershed size effect on regimes of water balance construction. As depicted in Fig. 10, we implemented water balance analyses for all four scenarios, i.e. April flood, June flood, April flood with June parameters, and June flood with April parameters.

Figure 10a demonstrates that the proportions of surface flow and initial abstraction follow a relation that decreases approximately monotonically with watershed size, with the exception of the configuration with 1 sub-basin which is regarded as one whole unit. This is because there is no channel within the watershed, and all of the water mass has to be lost at the hillslope. Meanwhile, ratios of baseflow and channel loss increase with increasing watershed size. Looking back at Figs. 7 and 9, parameters influencing surface flow (IA and LT) and channel transportation (K, CLR and CLF) both increase with basin area, indicating that both components of initial abstraction and channel loss would be increasing due to larger values of key parameters, which further implies that, with fewer partitions, more water tends to be abstracted on hillslope and then be infiltrated into baseflow, and that more water will be lost on the way to the outlet. 
Table 3. Parameter sensitivity indicators (\%).

\begin{tabular}{|c|c|c|c|c|c|c|c|c|c|}
\hline \multirow[t]{2}{*}{ Parameter variability } & & \multicolumn{2}{|c|}{ Surface flow } & \multicolumn{3}{|c|}{ Baseflow } & \multicolumn{3}{|c|}{ Flow in channel } \\
\hline & & IA & LT & IB & $\mathrm{RC}$ & $\mathrm{RP}$ & $\mathrm{K}$ & CLR & CLF \\
\hline \multirow[t]{2}{*}{ To basin sizes (PV) } & April & 266.2 & 198.4 & 213.0 & 5.0 & 82.9 & 217.6 & 366.7 & 166.5 \\
\hline & June & 539.8 & 209.1 & 266.2 & 7.2 & 79.6 & 224.8 & 357.0 & 126.8 \\
\hline To floods (PVf) & & -57.4 & -28.9 & -25.7 & -16.0 & 48.4 & -21.2 & -14.5 & 14.7 \\
\hline
\end{tabular}

(a) April flood with parameters of April

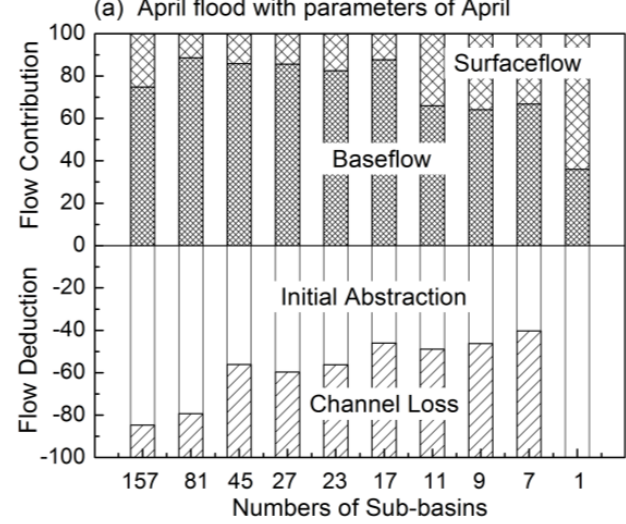

(c) April flood with parameters of June

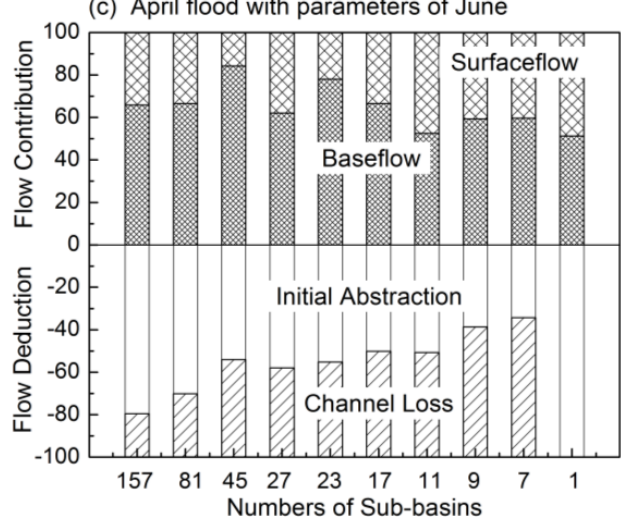

(b) June flood with parameters of June

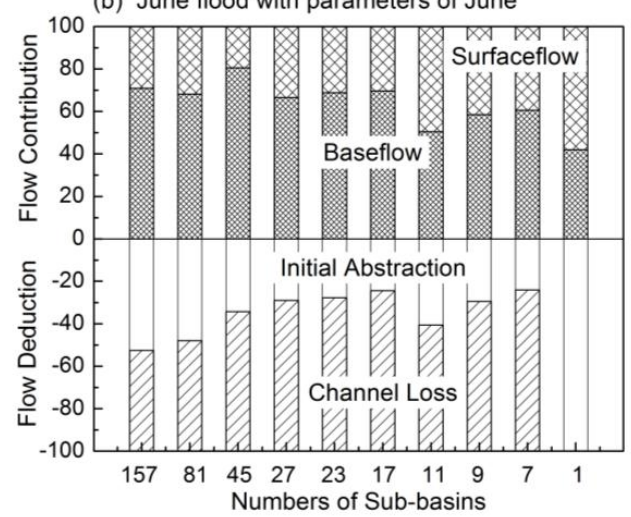

(d) June flood with parameters of April

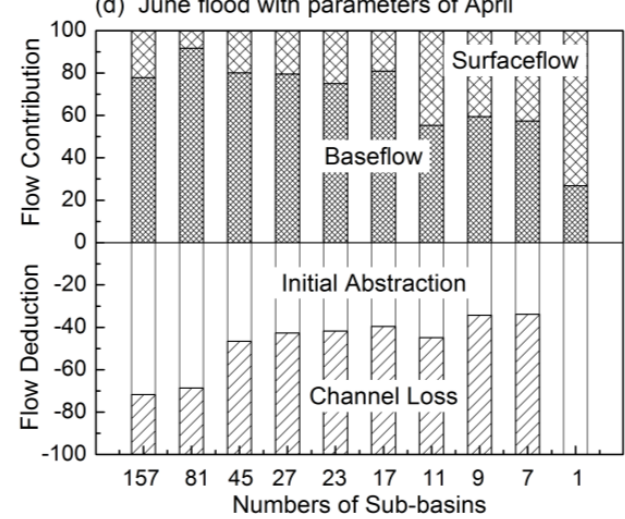

Fig. 10. Water balance - physical interpretation.

However, parameter sets of surface flow and baseflow yield an incorrect interpretation of the fraction of surface flow and the amount of baseflow. Figures 7 and 8 reveal that increasing trends hold for both parameter sets. Physically, an increase in abstraction induces a decrease in surface flow, while growth in baseflow parameters produces large baseflow rates. In this manner, the fraction of the surface flow to baseflow should be presented as a decreasing trend. In fact, an increasing tendency is observed in Fig. 10, demonstrating that automatically calibrated parameters in hydrological models can lead to an incorrect prescription of the internal dynamics of runoff production and transport.

Figure 10b depicts the fraction of water balance components for the June 2008 flood, during which tendencies of wa- ter balance components are similar to those of the April 2008 flood. The proportion values, however, are different. In April, the baseflow proportion is from $36.0 \%$ to $88.7 \%$, with an average of $73.8 \%$, while in June the baseflow is from $42.0 \%$ to $80.6 \%$ percent of total runoff, with an average of $63.6 \%$. Schilling and Libra (2003) found that the baseflow fraction at the Cedar River in Cedar Rapids (5 464 500), which is not far from the outlet of the Clear Creek Watershed (5 454300), was $62.1 \%$ from 1940 to 2000 , which is close to that of the June flood. Similarly, the fraction of initial abstraction for April is from $40.2 \%$ to $100 \%$, with an average of $61.7 \%$, and for the June flood the values range from $24.0 \%$ to $100 \%$, with an average of $41.0 \%$. The other two scenarios, the April flood with the parameters of June and the June flood with the 
parameters of April, demonstrate the same tendency of water balance components, and the fractions are confined by scenarios of the April and June floods.

\section{Conclusions}

This study investigates the effects of watershed subdivisions on HEC-HMS model calibrated parameters and the subsequent hydrologic processes and water balance components. Hydrologic simulations are conducted in CCW for two different floods: an extremely large flood in June 2008 and a relatively small flood in April 2008. Ten threshold areas are specified to delineate sub-watersheds; a trial-and-error method is used to automatically calibrate the HEC-HMS model; and hydrologic processes are evaluated in view of water balance components. The main findings are as follows:

1. Watershed subdivision affects drainage density and average longest flow, which represent the watershed attributes and model structure of the hydrologic model. Both drainage density and average longest flow follow power-law functions with respect to mean sub-basin areas.

2. A comparison of simulated hydrographs sketched in Figs. 5 and 6 shows little difference between most configurations, which can be further refined to obtain equal quality. However, configurations with 1 and 157 subbasins do not yield as good of results as the others, and we may expect a threshold level of sub-basin delineations beyond which model parameters have little possibility to enhance model performance. Similarly, this threshold level is also found to exist in SWAT (Jha et al., 2004).

3. Calibrated parameters were adjusted by the trial-anderror method implemented in the HEC-HMS model. The values of key calibrated parameters are sensitive to the watershed partition scheme as well as to flood event patterns. Results show that parameters corresponding to the hillslope have a larger variation for different floods than for parameters related to the river channel, while the latter parameter sets vary greatly when the watershed size changes.

4. The watershed partition affects hydrologic processes due to parameter changes; however, the parameter changes incorrectly describe the variation scheme of water balance components.

Acknowledgements. This research is supported by National Forestry Public Welfare Research Project from State Forestry Administration (201104005-01), P.R. China, Chinese National "Twelfth Five-Year" Plan for Science \& Technology Support (2012BAB04B01), and the Fundamental Research Funds for the
Central Universities (NO.BLX2012045), P.R. China. We gratefully acknowledge the Iowa Flood Center and IIHR-Hydroscience \& Engineering at The University of Iowa, USA, for their financial support for the main part of the research. The authors also thank Professor Larry Web and Dr. Ricardo Mantilla for their constructive advice and immense help to improve this study.

Edited by: A. Opere

\section{References}

Ao, T. Q., Yoshitani, J., Takeuchi, K., Fukami, K., Mutsuura, T., and Ishidaira, H.: Effects of sub-basin scale on runoff simulation in distributed hydrological model: BTOPMC, Weather Radar Information and Distributed Hydrological Modeling, IAHS-AISH Publication, 282, 1-7, 2003.

Chen, F., Xie, J., and Chen, X.: Effects of spatial scale on distributed flood simulation based on HEC-HMS Model: A Case of Jinjiang Watershed, Fujian, China, Geoinformatics, 19th International Conference, 1-5, 2011.

Chu, H. J. and Chang, L. C.: Applying Particle Swarm Optimization to Parameter Estimation of the Nonlinear Muskingum Model, J. Hydrol. Eng., 14, 1024-1027, 2009.

Cleveland, T. G., Luong, T., and Thompson, D. B.: Watershed subdivision for modeling, World Environmental and Water Resources Congress, Great Rivers, 6527-6536, 2009.

Cunge, J. A.: On the subject of a flood propagation computation method (Muskingum Method), J. Hydraul. Res., 7, 205-230, 1969.

Elliott, A. H., Trowsdale, S. A., and Wadhwa, S.: Effect of Aggregation of On-Site Storm-Water Control Devices in an Urban Catchment Model, J. Hydrol. Eng., 14, 975-983, 2009.

Gan, T. Y. and Biftu, G. F.: Automatic calibration of conceptual rainfall-runoff models: Optimization algorithms, catchment conditions, and model structure, Water Resour. Res., 32, 3513-3524, 1996.

Ghosh, I. and Hellweger, F. L.: Effects of spatial resolution in Urban hydrologic simulations, J. Hydrol. Eng., in press, 2011.

Hydrology National Engineering Handbook, Chapter 7: Hydrologic Soil Groups. National Resources Conservation Service, United States Department of Agriculture, 2007.

Jha, M., Gassman, P. W., Secchi, S., Gu, R., and Arnold, J.: Effect of watershed subdivision on SWAT flow, sediment, and nutrient predictions, J. Am. Water Resour. As., 40, 811-825, 2004.

Kalin, L. and Hantush, M. M.: Hydrologic Modeling of an Eastern Pennsylvania Watershed with NEXRAD and Rain Gauge Data, J. Hydrol. Eng., 11, 555-569, 2006.

Kumar, S. and Merwade, V.: Impact of watershed subdivision and soil data resolution on model calibration and parameter uncertainty, J. Am. Water Resour. As., 45, 1179-1195, 2009.

Lin, Y. and Mitchell, K. E.: The NCEP stage II/IV hourly precipitation analyses: Development and applications. Preprints, 19th Conf. on Hydrology, San Diego, CA, Am. Meteorol. Soc., 1.2. available at: http://ams.confex.com/ams/pdfpapers/83847. pdf (last access: 2005), 2005. 
Merwade, V.: Creating SCS Curve Number Grid using HECGeoHMS. School of Civil Engineering, Purdue University, available at: http://web.ics.purdue.edu/ $\sim$ vmerwade/education/cngrid. pdf, 2011.

Moradkhani, H., Hsu, K. L., Gupta, H., and Sorooshian, S.: Uncertainty assessment of hydrologic model states and parameters: Sequential data assimilation using the particle filter, Water Resour. Res., 41, W05012, doi:10.1029/2004WR003604, 2005.

Muleta, M. K., Nicklow, J. W., and Bekele, E. G.: Sensitivity of a distributed watershed simulation model to spatial scale, J. Hydrol. Eng., 12, 163-172, 2007.

Mutel, F. C.: A watershed Year: anatomy of the Iowa Floods of 2008, University of Iowa Press, 2010.

National Environmental Satellite, Data, and Information Service (NESDIS): 2008 Midwestern US floods. National Oceanic and Atmospheric Administration, National Climatic Data Center, available at: http://www.ncdc.noaa.gov/special-reports/ 2008-floods.html (last access: 9 July 2008), 2008.

Papanicolaou, A. N., Elhakeem, M., Wison, C. G., Burras C. L., and Oneal, B.: Observations of soils at the hillslope scale in the Clear Creek Watershed in Iowa, USA, Soil Survey Horizons, 49, 83-86, 2008.
Scharffenber, W., Ely, P., Daly, S., Fleming, M., and Pak, J.: Hydrologic modeling system (HEC-HMS): physically-based simulation components, 2nd Joint Federal Interagency Conf., Las Vegas, NV, 2010.

Schilling, K. E. and Libra, D. L.: Increased baseflow in Iowa over the second half of the 20th century, J. Am. Water Resour. As., 39, 851-860, 2003.

Tripathi, M. P., Raghuwanshi, N. S., and Rao, G. P.: Effect of watershed subdivision on simulation of water balance components, Hydrol. Process., 20, 1137-1156, 2006.

USACE: Hydrologic Modeling System HEC-HMS. Technical Reference Manual, US Army Corps of Engineers, Hydrologic Engineering Center, 41-104, 2000.

Vrugt, J. A., Gupta, H. V., Bouten, W., and Sorooshian, S.: A shuffled complex evolution metropolis algorithm for optimization and uncertainty assessment of hydrologic model parameters, Water Resour. Res., 39, 1021, doi:10.1029/2002WR001642, 2003. 